Please do not remove this page

RMIT

UNIVERSITY

\title{
Anelasticity of die-cast magnesium-aluminium based alloys under different strain rates
}

ANG, Hua Qian; Abbott, Trevor; Zhu, Suming; Easton, Mark

https://researchrepository.rmit.edu.au/esploro/outputs/9921862979401341/filesAndLinks?institution=61RMIT_INST\&index=null

ANG, H. Q., Abbott, T., Zhu, S., \& Easton, M. (2017). Anelasticity of die-cast magnesium-aluminium based alloys under different strain rates. Materials Science and Engineering: A, 707, 101-109.

https://doi.org/10.1016/j.msea.2017.09.012

Document Version: Accepted Manuscript

Published Version: https://doi.org/10.1016/j.msea.2017.09.012

Repository homepage: https://researchrepository.rmit.edu.au

CC BY-NC-ND V4.0

(C) 2017 Elsevier B.V. All rights reserved.

Downloaded On 2023/04/26 19:44:28 +1000 


\title{
Anelasticity of die-cast magnesium-aluminium based alloys under different strain rates
}

\author{
Hua Qian Anga, Trevor B. Abbott ${ }^{\mathrm{a}, \mathrm{b}}$, Suming Zhu ${ }^{\mathrm{a}}$, Mark A. Easton ${ }^{\mathrm{a}, *}$ \\ ${ }^{a}$ School of Engineering, RMIT University, Bundoora, Victoria 3083, Australia \\ ${ }^{b}$ Magontec Limited, Sydney, New South Wales 2000, Australia
}

\begin{abstract}
Cyclic tension loading-unloading tests were conducted over a wide quasi-static strain rate range $10^{-6}-10^{-1} \mathrm{~s}^{-1}$ on a variety of die-cast $\mathrm{Mg}$-Al based alloys, from which the deformation behaviour, especially the anelasticity, has been systematically studied. At the early stages of deformation, prior to the onset of extensive prismatic slip, the anelastic strain is less dependent on strain rate but varies between the alloys. Upon the activation of extensive prismatic slip, the anelastic strain starts to saturate at a maximum. The maximum increases with increasing strain rate and varies between alloys. The strain-rate dependence of the maximum anelastic strain can be interpreted in terms of solid solution softening/hardening of slip planes and their influence on twinning. Implications of the strain-rate dependence of anelasticity on proof stress measurement of $\mathrm{Mg}$ alloys are also discussed.
\end{abstract}

Keywords: Magnesium alloys; Anelasticity; Twinning; Strain-rate sensitivity; High-pressure die-casting;

* Corresponding author. Tel: +61 399256278

E-mail address: mark.easton@rmit.edu.au 


\section{Introduction}

The deformation behaviour of magnesium $(\mathrm{Mg})$ alloys is complex due to limited dislocation slip systems [1], leading to difficulties in measuring yield strength [2] and perceived limits to ductility. The limited slip systems results in the activation of twinning to accommodate plastic deformation and the stress-strain curves can be divided into several segments [3-5]. Initial deformation is elastic (stage I) followed by a non-linear region (stage II) in which basal slip and twinning are the dominant deformation mechanisms [6-10]. The twins formed in this region are not stable [11] and can revert during unloading [12], making a large part of stage II deformation reversible. At higher stresses, deformation via prismatic slip takes place leading to extensive plastic deformation (stage III) [3, 13]. Eventually the onset of dynamic recovery via the activation of pyramidal slip leads to the final stage of deformation before fracture (stage IV) [13-15].

The focus of this paper is on the reversible component of stage II deformation. The terms anelastic and pseudo-elastic have been used in the past to describe this component [1620]. The study of anelasticity in stage II is important as it influences several properties including yield strength [2], fatigue strength [21], apparent stiffness [16, 17] and sound dampening [11]. The anelastic behaviour of $\mathrm{Mg}$ alloys, which manifests as hysteresis loops in loading-unloading stress-strain curves, has been observed in pure $\mathrm{Mg}$ and $\mathrm{Mg}-\mathrm{Zn}$ alloys [17], Mg-Al alloys [22], AZ31 (Mg-3Al-1Zn) [9], AZ91 (Mg-9Al-0.6Zn) [16], AM60B (Mg-6Al$0.3 \mathrm{Mn})$ and AE44 (Mg-4Al-4RE) [21].

This study focuses on high-pressure die-cast alloys. Die-cast alloys account for the large majority of $\mathrm{Mg}$ alloy usage and anelasticity contributes significantly to deformation due to the fine grain size. Experiments on pure Mg [23] and die-cast AZ91 [16] have shown that the anelastic effect is more significant in fine-grained alloys. The increase in anelasticity in finegrained AZ91 was attributed to the formation of fine and unstable twins, which are more prone to revert upon unloading [16]. Anelasticity is also influenced by solute content. The largest anelastic effect has been observed in pure $\mathrm{Mg}$ and decreased with increasing $\mathrm{Zn}$ [17] and Gd [19] solute concentrations. It was proposed that introduction of solute in solution can lower the critical resolved shear stress (CRSS) for prismatic slip. Consequently, twinning becomes less necessary during deformation, lowering the amount of reversible twinning. Although there was a monotonic decrease in anelasticity with increasing $\mathrm{Zn}$ and Gd contents, a similar trend was not observed in $\mathrm{Mg}-\mathrm{Al}$ alloys; both $\mathrm{Mg}-0.5 \mathrm{Al}$ and $\mathrm{Mg}-2 \mathrm{Al}$ alloys showed similar anelasticity despite the difference in Al content [22]. However, the study was complicated by the fact that the grain size of the $\mathrm{Mg}-0.5 \mathrm{Al}$ alloy was three times larger than that of the $\mathrm{Mg}-2 \mathrm{Al}$ alloy. Anelasticity of $\mathrm{Mg}$ alloys has also been observed to be more pronounced in compression than in tension $[16,17]$, due to increased activity of $\{10 \overline{1} 2\}$ twinning [24].

Recently, the effects of strain rate on the tensile properties and deformation microstructures of a range of $\mathrm{Mg}$ die-casting alloys including AM40 (Mg-4Al-0.3Mn), AM60, AZ91, and AE44 (as cast and T5 aged) have been studied by the present authors over a wide strain rate range $10^{-6}-10^{-1} \mathrm{~s}^{-1}$ [25]. It was shown that strain-rate sensitivity decreases with increasing $\mathrm{Al}$ solute level in the alloys, due to dynamic strain ageing from the interaction 
between Al solute and dislocations. It was also shown that deformation twinning is more active in alloys with higher $\mathrm{Al}$ solute levels.

The focus of the present work is on the anelastic behaviour of $\mathrm{Mg}$ die-casting alloys under a similar strain rate range. The selection of these alloys was influenced in part by their use as commercial alloys, but principally to examine a range of alloy behaviours. AM40, AM60 and AE44-F have moderate strength but good ductility, while AZ91 and AE44-T5 are higher-strength alloys. The strengthening mechanisms within these two alloys are very different with AE44-T5 strengthened by nanoscale precipitates [26] while AZ91 is strengthened, at least in part, by an intermetallic skeleton [27, 28]. Comparisons of the amount of anelasticity in these alloys can yield insights into the deformation mechanisms.

\section{Materials and Experimental Details}

Mg alloys AM40, AM60, AZ91 and AE44 were high-pressure die-cast in a 250 ton cold chamber machine. More details about the casting process can be found elsewhere [29]. The chemical compositions of these alloys were analysed by inductively coupled plasma atomic emission spectroscopy (ICP-AES) and are listed in Table 1. AE44 specimens were also given an ageing treatment for $32 \mathrm{~h}$ at $200{ }^{\circ} \mathrm{C}$ (labelled T5).

Cast-to-size cylindrical cross section, dog-bone shaped tensile samples, $100 \mathrm{~mm}$ in length with a $36 \mathrm{~mm}$ parallel section in the gauge length and a diameter of $5.6 \mathrm{~mm}$ were used in this study. Monotonic and cyclic tension loading-unloading tests were performed on an Instron 5569 universal testing machine with a $50 \mathrm{kN}$ load cell at room temperature using a constant rate of crosshead displacement with nominal strain rates in the range from $10^{-6}$ to $10^{-}$ ${ }^{1} \mathrm{~s}^{-1}$. For the cyclic loading-unloading tests, the samples were loaded to a predetermined strain, unloaded to zero stress and then reloaded again. All alloys were cyclically tested to $3 \%$ strain, except AZ91, which was tested to a higher strain (4.5\%) in order to determine saturation of anelasticity. Each test was repeated at least twice to ensure reproducibility. Compression tests were not conducted in this study as high-pressure die-cast alloys are relatively isotropic in mechanical properties [30, 31].

Deformation microstructures of AE44 after cyclic testing to $3 \%$ strain at different strain rates were characterised by electron-backscattered diffraction (EBSD) and transmission electron microscopy (TEM). EBSD data was collected in a FEI Nova NanoSEM at 20kV using a $0.5-\mu \mathrm{m}$ step size. HKL Channel 5 Tango subroutine was used to identify the twinning types based on the misorientation angle/axis between the twinned region and matrix. They are $\{10 \overline{1} 2\}$ twins (i.e. $86^{\circ}<12 \overline{1} 0>$ ), $\{10 \overline{1} 1\}$ twins (i.e. $56^{\circ}<12 \overline{1} 0>$ ) and $\{10 \overline{1} 3\}$ twins (i.e. $64^{\circ}$ $\langle 12 \overline{1} 0>$ ) [32-34]. The surfaces of all samples for EBSD analysis were prepared using standard mechanical polishing procedures and were finished by $0.06 \mu \mathrm{m}$ OP-S. For TEM, the foils were cut from tested specimens and were prepared by ion milling using a Gatan Precision Ion Polishing System (PIPS) at $4 \mathrm{keV}$ with an incident angle of $4^{\circ}$. The thin foils were examined in a JEOL 2100F TEM. 


\section{Results}

Fig. 1 shows a typical loading-unloading hysteresis loop for AE44 at $10^{-4} \mathrm{~s}^{-1}$. Several relevant parameters are defined where the total strain $\left(\varepsilon_{\mathrm{t}}\right)$, is separated into three parts: linear elastic strain $\left(\varepsilon_{\mathrm{e}}\right)$, anelastic strain $\left(\varepsilon_{\mathrm{ae}}\right)$ and plastic strain $\left(\varepsilon_{\mathrm{p}}\right)$. Also shown is the corresponding monotonic flow curve. The monotonic flow curve follows closely the cyclic one, indicating that cyclic loading does not have an additional effect on the overall deformation behaviour.

Figs. 2(a) and (b) show the monotonic flow curves of AZ91 and AE44, respectively to illustrate the two extremes of behaviour observed in these experiments. The flow curves of as-cast AE44 consistently shift higher with increasing strain rate while the changes in the flow curves of AZ91 are marginal. The flow curves of aged AE44-T5 show slightly higher strain-rate dependence than that of AE44, while the flow curves of AM40 and AM60 behave more like AZ91, which show a much lower influence of strain rate. Cyclic flow curves (not shown) exhibit the same strain-rate effect as monotonic flow curves.

The monotonic flow curve can also be separated into different stages based on the Kocks-Mecking method of analysis [35, 36] extended by Cáceres and his co-workers [3, 13, 37] for Mg polycrystals. Determination of these stages is illustrated in Figs. 2(c) and (d). Assuming the elastic fraction, $f$, of the alloy deforms with an elastic modulus, $E=45 \mathrm{GPa}$ [38, 39], and the plastically deforming fraction strain hardens at a rate of, $\Theta_{\mathrm{h}}=1.4 \mathrm{GPa}$ (pure $\mathrm{Mg}$ polycrystals) [3-5], $f$ can be calculated [3]:

$$
f=\frac{\frac{\mathrm{d} \sigma}{\mathrm{d} \varepsilon}-\Theta_{\mathrm{h}}}{E-\Theta_{\mathrm{h}}}
$$

Where $\sigma$ and $\varepsilon$ are true stress and strain, respectively. The alloys are fully elastic (stage I) up to $\sim 65 \mathrm{MPa}$ for $\mathrm{AZ91}$ and $\sim 45 \mathrm{MPa}$ for AE44. The departure from pure elasticity indicates the onset of stage II. During stage II, the elastic fraction decreases rapidly due to basal slip and twinning [3-5, 37, 40, 41] and possibly a small amount of prismatic slip. The elastic fraction reaches zero when the alloy becomes fully plastic due to extensive prismatic slip (stage III) [3]. The onsets of these stages are also shown in Figs. 2(a) and (b) and onset values reported in Table 2. Upon extensive activation of prismatic slip, the strain hardening rate becomes constant (dashed line, prismatic slip-dominated region) at $1.6 \mathrm{GPa}$ in AZ91 and 1.2-1.6 GPa (depending on the strain rate) in AE44, close to the expected value of 1.4 GPa, a value commensurate with athermal accumulation of forest dislocations [5, 13]. Comparing AZ91 with AE44, it is interesting to note that in AZ91, the decrease of the elastic fraction towards zero is more asymptotic, indicating a gradual transition from stage II to stage III.

Fig. 3 shows the anelastic strain, $\varepsilon_{\text {ae }}$ (defined in Fig. 1) as a function of applied strain at strain rates spanning $10^{-6}-10^{-1} \mathrm{~s}^{-1}$. The onset of stage III defined in Fig. 2 is also marked on the anelastic curves. As observed, the anelastic strain saturates at between $0.2 \%$ and $0.45 \%$, depending on the alloy and strain rate, after a total strain of 1.5-2\%. For a given alloy, the maximum value of anelastic strain increases with strain rate; the changes of this maximum value against strain rate are greatest in aged AE44-T5, followed by AE44, while the changes are lower in AM40, AM60 and AZ91, consistent with the changes in cyclic and monotonic flow curves. While the maximum anelastic strain varies with strain rate, it is interesting to 
note that anelastic strain is less dependent on strain rate at the early stages of deformation prior to the onset of stage III.

To analyse the difference in deformation microstructures at different strain rates, high strain rate-sensitive alloy, AE44 was examined by EBSD and TEM after cyclic testing to 3\% strain as shown in Figs. 4 and 5, respectively. From EBSD analysis, it can be observed that the starting microstructure is twin-free; different types of twins are formed after cyclic tensile deformation with predominance of $\{10 \overline{1} 2\}$ extension twins. $\{10 \overline{1} 2\}$ extension twins are also most affected by strain rate (Table 3 ) which increase with increasing strain rate. $\{10 \overline{1} 2\}$ extension twinning is more reversible than other twinning types $[20,42]$ because of the near $90^{\circ}$ reorientation $\left(86.3^{\circ}\right)$ of the basal pole $[33,34]$. The increase of $\{10 \overline{1} 2\}$ twinning with strain rate had also been reported for die-cast AM60 and AZ91 in our previous study [25], although the increase is less in a low strain rate-sensitive alloy AZ91. In TEM images shown in Fig. 5, more dislocations pile-ups are observed when viewed with $\mathbf{g}=[10 \overline{1} 1]$. Most dislocation pile-ups become invisible when viewed with $\mathbf{g}=$ [0002], indicating that they are basal dislocations. Those dislocations that are still visible when viewed with $\mathbf{g}=[0002]$ are prismatic slip. It is clear that deforming at higher strain rates results in more dislocation pileups at twin and grain boundaries.

\section{Discussion}

The results presented here show that anelasticity is not very strain-rate dependent prior to the onset of stage III (extensive prismatic slip). Upon the onset of stage III, anelasticity starts to saturate, and the maximum anelasticity is strain-rate dependent, suggesting that prismatic slip may influence the anelasticity. In another hexagonal closed-packed metal, Zirconium (Zr) [43], it was observed that a small amount of slip in the $\mathrm{Zr}$ matrix may relax the internal stresses which are required to revert the twins during unloading. In this manner, slip dislocations might affect twin reversion. Similarly, later work on pure $\mathrm{Mg}$ and $\mathrm{Mg}-\mathrm{Zn}$ alloys [17] and die-cast AZ91 [16] showed a relationship between reversible twinning and prismatic slip. Easier prismatic slip was thought to reduce the tendency for twinning to occur as a deformation mechanism, with the net result being reduced reversible twinning. The discussion will now consider how strain rate and alloy content affect slip, which in turn results in changes in twinning and consequently anelasticity.

\subsection{The Effect of Strain Rate}

Prior to the onset of stage III, the changes in anelastic strain with strain rate are smaller (Fig. 3). This is because in stage II, basal slip and twinning are the dominant deformation mechanisms [5, 37, 40, 41]. Since it is well-known that CRSS of basal slip and twinning are strain-rate independent [44-48], it would be expected that the anelastic strain in this region is strain-rate independent. The small variations in anelastic strain in this region could be due to small strain-rate effect of basal slip or presence of small amount of prismatic slip. The latter may be the case for AZ91, which shows a gradual transition from stages II to III (Fig. 2(c)), indicating that prismatic slip may activate early, leading to some strain-rate sensitivity even before the onset of stage III. 
Upon onset of stage III, twinning starts to saturate as extensive prismatic slip is activated. Extensive prismatic slip can also reduce the twin boundary mobility [43], and therefore, the anelastic strain starts to saturate (Fig. 3).

The maximum anelasticity then increases with increasing strain rate in the studied alloys. This is due to a delay in the onset of stage III with increasing strain rate, as indicated by the higher onset stress and strain (Figs. 2(a) and (b)). Dislocations are thermally activated [49]. As strain rate increases, there is less time for thermal activation of slip [50], making prismatic slip more difficult to activate at higher strain rates. The CRSS of prismatic slip has also been reported to be dependent on strain rate [44, 46]. Firstly, difficulty in activation of prismatic slip at higher strain rate increases the alloys' tendency to twin, in particular $\{10 \overline{1} 2\}$ twins as shown in Fig. 4 and Table 3. Secondly, the increased dislocation pile-ups at twin and grain boundaries at higher strain rates (Fig. 5) could increase the internal back stresses [51]. Internal back stresses are required to revert the twins [18]. Both phenomena can increase the amount of reversible twinning (larger maximum anelastic strain) at higher strain rates (Fig. $3)$.

\subsection{Inter-alloy Comparison}

Comparison of Mg-Al alloys AM40, AM60 and AZ91 without RE addition showed that the linear elastic region is extended with increasing $\mathrm{Al}$ content due to a delay in the stage II onset (Fig. 6(a)). This suggests that AZ91 has a larger elastic region in comparison with AM40 and AM60. The delay in the stage II onset also reduces the anelasticity in AZ91 at low stresses (Fig. 6(b)). However, AZ91 shows the largest maximum anelastic strain, i.e. the amount at saturation, while AM60 and AM40 show similar maximum anelastic strain (Fig. 7).

The grain sizes of these alloys are similar $(\sim 8 \mu \mathrm{m})$ so the main difference is the $\mathrm{Al}$ content. The major effect of $\mathrm{Al}$ at high concentrations such as $9 \mathrm{wt} . \%$ (AZ91) is solid solution hardening of slip planes [18]. This explains the higher onsets of stage II and III deformation, implying that both basal and prismatic slip are becoming more difficult, respectively. However, $\mathrm{Al}$ has little hardening effect on twinning as $\mathrm{Al}$ forms near-random solid solutions [52] and does not develop short-range order (SRO) [53]. \{1012\} twinning is shuffling dominated $[54,55]$ and it becomes more difficult when SRO is present. Since both basal and prismatic slip are more difficult in AZ91 while twinning is not hardened by Al; the relative propensity for twinning increases, thereby increasing the maximum anelastic strain.

Another notable observation is the similar maximum anelastic strain in AM40 and AM60 (Fig. 7), despite a notable difference in Al content. This can be rationalised as follows. Additional Al solute up to $2 \mathrm{wt} . \%$ was found to soften prismatic planes [22], and since $\mathrm{Al}$ solute above 9 wt.\% can harden slip planes [18], the present work suggests that there is a transition from softening to hardening of prismatic planes with increasing $\mathrm{Al}$ concentration from 2-9 wt.\%. It is likely that both AM40 and AM60 are near the softening-hardening transition point in which $\mathrm{Al}$ content has less of an effect on slip planes, and hence they have similar maximum anelastic strain. This hypothesis is further supported by the fact that there is barely any difference between the onsets of stages II and III in AM40 and AM60 (Fig. 6(a)).

Another conundrum arising from the present results is that both AE44 and AE44-T5 have smaller maximum anelastic strain below $10^{-3} \mathrm{~s}^{-1}$; whilst above $10^{-3} \mathrm{~s}^{-1}$, the maximum 
anelastic strain is observed to increase to be greater than that found in AM40 and AM60 (Fig. 7). AE44, which has a lower amount of $\mathrm{Al}$ in solid solution [25], consists of Al-RE intermetallics which are not found in the AM40, AM60 and AZ91 alloys [56, 57]. Recent studies on other die-cast $\mathrm{Mg}$ alloys showed a measurable strengthening effect of the percolating intermetallic [27, 28, 58, 59], but it is not known if it has an effect on the anelastic deformation. Comparison between $\mathrm{Mg}$-Al-RE and $\mathrm{Mg}-\mathrm{Al}$ alloys is more complex due to the microstructural differences, and requires further investigation.

Interestingly, in Fig. 7, the increase in the maximum anelastic strain with strain rate is smaller when the prismatic slip (stage III) onset is less strain-rate sensitive, e.g. in AM40, AM60, and AZ91. This further proves that prismatic slip has an indirect effect on the overall anelastic behaviour. The question of interest here is why prismatic slip is more strain-rate sensitive in AE44 and T5-aged AE44. The effect of strain rate on the tensile behaviour of similar die-cast alloys has been investigated in previous work [25], which showed that increasing $\mathrm{Al}$ in solution decreases the strain-rate sensitivity in stage III. The reduction in strain-rate sensitivity was explained by dynamic strain ageing due to the interaction of $\mathrm{Al}$ solute with dislocations [25]. Both AE44 and AE44-T5 have very little Al solute in the $\alpha-\mathrm{Mg}$ matrix, especially in the T5 condition where even more solute is removed as a result of precipitation [26]. Consequently, as previously reported [25] these alloys are less likely to be affected by dynamic strain ageing and the intrinsic strain-rate sensitivity in $\mathrm{Mg}$ which is often attributed to the hexagonal closed-packed crystal structure [60] is manifested, especially in the stage III region. Overall, it is the strain-rate dependence of prismatic slip that leads to a variation in maximum anelasticity with strain rate, even though twinning is strain-rate insensitive.

\subsection{Effect of Precipitation}

It has recently been observed that a T5 heat treatment leads to a significant increase in the strength of AE44 with the main change in microstructure being the precipitation of Al-Mn phases and a consequent reduction in solute in the matrix [26]. In Fig. 6(a), the onset of stage II deformation in AE44 and AE44-T5 occurs at stresses $\sim 45 \mathrm{MPa}$ and $\sim 70 \mathrm{MPa}$, respectively. The extended linear elastic region in AE44-T5 suggests that basal slip is delayed, presumably due to precipitation hardening. Besides the hardening of basal slip, there is also evidence of hardening of prismatic slip (higher onset of stage III) in AE44-T5. Since both basal and prismatic slip are more difficult in AE44-T5, the total amount of anelastic strain in AE44-T5 should be more than that in AE44 given the argument provided for AZ91, but the present results (Fig. 7) suggest otherwise.

The lower maximum anelastic strain in AE44-T5 compared to AE44 suggests a reduced tendency to de-twin in AE44-T5. In the presence of precipitates, twinning will encounter these precipitates as it propagates along the twin boundaries [61]. An additional stress is required to bow twinning around the particles. If twinning is more difficult due to the presence of precipitates, the amount of de-twinning and consequently anelasticity will also reduce.

In fact, studies have shown that precipitates can suppress different deformation mechanisms, depending on the precipitate morphology [62, 63]. For example, rod-like precipitates are more effective in strengthening basal slip than prismatic slip [64], while 
plate-like precipitates are more effective in inhibiting twinning compared to sphere-like precipitates [61]. The AE44-T5 alloy used in the present study has been characterised by TEM and results showed that the Al-Mn precipitates formed in this alloy are nano-scale particles [26]. Hence, they are likely to have the same strengthening effect on any deformation modes. The presence of precipitates may suppress all deformation mechanisms, leading to a smaller total strain at a given stress (comparing AE44 and AE44-T5 in Fig. 6(a)).

\subsection{The Effect of Anelastic Strain on the Offset Strain for Proof Stress Measurement}

The presence of anelasticity in $\mathrm{Mg}$ and its alloys has been observed to delay the onset of yielding and make proof stress measurement difficult [2]. A more accurate and consistent proof stress measurement method was previously proposed and it was shown that an appropriate offset strain for $0.2 \%$ proof stress should always consider the anelasticity at $0.2 \%$ plastic strain [2]. Since the present results show a change in anelastic strain with strain rate, the appropriate offset strain to achieve a $0.2 \%$ permanent strain proof stress for AZ91 and AE44 can range from $0.39-0.48 \%$ and $0.37-0.51 \%$ respectively, depending on the applied strain rate as shown in Fig. 8. A wider range of offset strain in AE44 compared to AZ91 is a consequence of a larger variation in anelastic strain due to the high strain-rate dependence of prismatic slip in AE44.

\section{Conclusions}

The anelasticity of commercial die-cast $\mathrm{Mg}-\mathrm{Al}$ based alloys has been studied across quasi-static strain rates $10^{-6}-10^{-1} \mathrm{~s}^{-1}$. The following conclusions are drawn from this study:

1. Anelastic strain increases with stress and strain at early stages of deformation when basal slip and twinning dominate. The strain-rate insensitivity of these two deformation modes results in little variation of anelastic strain with strain rate in this region. As deformation continues, the anelasticity begins to saturate to a maximum upon activation of extensive prismatic slip. The strain-rate sensitivity of prismatic slip leads immediately to the high strain-rate dependence of maximum anelastic strain.

2. AZ91 has smaller anelastic strain at low stress levels, but it exhibits the largest maximum anelastic strain, when compared to AM40 and AM60. It is proposed that at low Al contents, solution softening of the prismatic planes reduces the need to twin, whereas at the higher concentrations, solid solution hardening in all slip systems (but not twinning) makes dislocation slip more difficult, leading to an increased amount of twinning. The small anelastic strain of AZ91 at low stresses is due to its extended linear elastic region, resulting in a delay in the onset of anelasticity.

3. The presence of precipitates in aged AE44-T5 is observed to harden not only basal and prismatic slip, but also suppress twinning, lowering the anelastic strain in comparison with as-cast AE44.

4. The variation in anelastic strain with strain rate leads to a wide range of offset strains required to achieve a $0.2 \%$ permanent strain proof stress even for the same alloy. 


\section{Acknowledgements}

This work was supported by the Australian Research Council [Grant number LP130100828]. The samples were produced by the CSIRO Manufacturing Flagship with acknowledgement of Mr. Gary Savage and Mr. Andrew Yob. The authors would like to thank Dr. Carlos Cáceres from the University of Queensland for his very helpful comments on the manuscript. 


\section{References}

[1] P.G. Partridge, The crystallography and deformation modes of hexagonal close-packed metals, Metall. Rev. 12 (1967) 169-194.

[2] H.Q. Ang, T.B. Abbott, S.M. Zhu, C.F. Gu, M.A. Easton, Proof stress measurement of die-cast magnesium alloys, Mater. Des. 112 (2016) 402-409.

[3] K.V. Yang, C.H. Cáceres, A.V. Nagasekhar, M.A. Easton, Low-strain plasticity in a high pressure die cast Mg-Al alloy, Model. Simul. Mater. Sci. Eng. 20 (2012) 024010.

[4] K.V. Yang, C.H. Cáceres, C.N. Tomé, The elasto-plastic transition in magnesium alloys, in: Mathaudhu SN, Sillekens WH, Neelameggham NR, Hort N (Eds.), Magnesium Technology 2012: Proceedings of the TMS (The Minerals, Metals \& Materials Society), 2012 Mar 11-15, Orlando, Florida. John Wiley and Sons, New York, 2012, pp. 127-131.

[5] C.H. Cáceres, P. Lukáč, Strain hardening behaviour and the Taylor factor of pure magnesium, Philos. Mag. 88 (2008) 977-989.

[6] I.J. Polmear, Light alloys: metallurgy of the light alloys, Metall. Mater. Sci. (1995) 16895.

[7] M. Pekguleryuz, K. Kainer, A. Kaya, Fundamentals of magnesium alloy metallurgy, first ed., Woodhead Publishing, Cambridge, 2013.

[8] M.H. Yoo, Slip, twinning, and fracture in hexagonal close-packed metals, Metall. Trans. A. 12 (1981) 409-418.

[9] J. Koike, N. Fujiyama, D. Ando, Y. Sutou, Roles of deformation twinning and dislocation slip in the fatigue failure mechanism of AZ31 Mg alloys, Scri. Mater. 63 (2010) 747-750.

[10] J.W. Christian, S. Mahajan, Deformation twinning, Prog. Mater. Sci. 39 (1995) 1-157.

[11] T.W. Duerig, R. Zadno, An engineer's perspective of pseudoelasticity, in: T.W. Duerig, K.N. Melton, D. Sto ckel, C.M. Wayman (Eds.), Engineering aspects of shape memory alloys, Butterworth-Heinemann Publisher, Oxford, 1990, pp. 369-393.

[12] O. Muránsky, D.G. Carr, P. Šittner, E.C. Oliver, In situ neutron diffraction investigation of deformation twinning and pseudoelastic-like behaviour of extruded AZ31 magnesium alloy, Int. J. Plast. 25 (2009) 1107-1127.

[13] C.H. Cáceres, A.H. Blake, On the strain hardening behaviour of magnesium at room temperature, Mater. Sci. Eng. A. 462 (2007) 193-196.

[14] B.C. Wonsiewicz, Plasticity of magnesium crystals [dissertation], Massachusetts Institute of Technology, Cambridge, 1966.

[15] G. Dieter, Mechanical Metallurgy, SI Metric ed., McGraw-Hill, London, 1988.

[16] C.H. Cáceres, T. Sumitomo, M. Veidt, Pseudoelastic behaviour of cast magnesium AZ91 alloy under cyclic loading-unloading, Acta Mater. 51 (2003) 6211-6218.

[17] G.E. Mann, T. Sumitomo, C.H. Cáceres, J.R. Griffiths, Reversible plastic strain during cyclic loading-unloading of Mg and Mg-Zn alloys, Mater. Sci. Eng. A. 456 (2007) 138146.

[18] D. Nagarajan, X. Ren, C.H. Cáceres, Anelastic behavior of Mg-Al and Mg-Zn solid solutions, Mater. Sci. Eng. A 696 (2017) 387-392.

[19] D. Nagarajan, Anelasticity in cast Mg-Gd alloys, Mater. Sci. Eng. A 695 (2017) 14-19.

[20] S.Y. Lee, M.A Gharghouri, Pseudoelastic behavior of magnesium alloy during twinning-dominated cyclic deformation, Mater. Sci. Eng. A. 572 (2013) 98-102.

[21] Z. Lu, P. Blackmore, Cyclic stress-strain behaviour of AM60B and AE44 cast magnesium alloys and its impact on LCF characterisation and fatigue analysis, SAE Int. J. Mater. Manuf. 7 (2014) 446-53. 
[22] D. Nagarajan, C.H. Cáceres, J.R. Griffiths, Anelastic phenomena in Mg Al alloys, in: F. Chmelík, R. Král, J.L. Martin (Eds.), Proceedings of the 12th International Symposium on Physics of Materials, Acta Phys. Polonica A. 122 (2012) No. 3.

[23] C.H. Cáceres, G.E. Mann, J. Griffiths, Grain size hardening in Mg and Mg-Zn solid solutions, Metall. Mater. Trans. A. 42 (2011) 1950-1959.

[24] S.R. Agnew, Ö. Duygulu, Plastic anisotropy and the role of non-basal slip in magnesium alloy AZ31B, Int. J. Plast. 21 (2005) 1161-1193.

[25] H.Q.Ang, S.M.Zhu, T.B.Abbott, D.Qiu, M.A.Easton, Strain-rate sensitivity of die-cast magnesium-aluminium based alloys, Mater. Sci. Eng. A. 699 (2017) 239-246.

[26] S.M. Zhu, T.B. Abbott, M.A. Gibson, J.F. Nie, M.A. Easton, Age hardening in die-cast Mg-Al-RE alloys due to minor Mn additions, Mater. Sci. Eng. A. 656 (2016) 34-38.

[27] B. Zhang, A.V. Nagasekhar, T. Sivarupan, C.H. Cáceres, Deformation behavior of the percolating intermetallic microstructure of high pressure die cast AZ91 alloy, Adv. Eng. Mater. 15 (2013) 1059-1067.

[28] B. Zhang, K.V. Yang, A.V. Nagasekhar, C.H. Cáceres, M.A. Easton, Deformation behavior of the percolating eutectic intermetallic in HPDC and squeeze-cast Mg alloys, J. Metals. 66 (2014) 2086-2094.

[29] A.V. Nagasekhar, M.A. Easton, C.H. Cáceres, Solute content and the grain microstructure of high pressure die cast magnesium-aluminium alloys, Adv. Eng. Mater. 11 (2009) 912-919.

[30] C. Dørum, O.S. Hopperstad, O.G. Lademo, M. Langseth, Numerical modelling of the structural behaviour of thin-walled cast magnesium components, Int. J. Sol. Struct. 42 (2005) 2129-2144.

[31] M.A. Easton, W.Q. Song, T.B. Abbott, A comparison of the deformation of magnesium alloys with aluminium and steel in tension, bending and buckling, Mater. Des. 27 (2006) 935-946.

[32] C.S. Roberts, Magnesium and its Alloys, John Wiley \& Sons, New York, 1960.

[33] B.C. Wonsiewicz, W.A. Backofen, Independent slip systems and ductility of hexagonal polycrystals, Trans. Metall. Soc. AIME 239 (1967) 1422-1433.

[34] M.D. Nave, M.R. Barnett, Microstructures and textures of pure magnesium deformed in plane-strain compression, Scr. Mater. 51 (2004). 881-885.

[35] U.F. Kocks, The relation between polycrystal deformation and single-crystal deformation, Metall. Mater. Trans. 1 (1970) 1121-1143.

[36] U.F. Kocks, H. Mecking, Physics and phenomenology of strain hardening: the FCC case, Prog. Mater. Sci. 48 (2003) 171-273.

[37] C.H. Cáceres, P. Lukáč, A.H. Blake, Strain hardening due to $\left\{\begin{array}{llll}10 & 1 & 2\end{array}\right\}$ twinning in pure magnesium, Philos. Mag. 88 (2008) 991-1003.

[38] M. Avedesian, H. Baker, Magnesium and magnesium Alloys-ASM Specialty Handbook, Vol. 52, ASM International. Ohio: The Materials Information Society, 1999.

[39] T. Sumitomo, C.H. Cáceres, M. Veidt, The elastic modulus of cast Mg-Al-Zn alloys, J. Light Metals. 2 (2002) 49-56.

[40] S.R. Agnew, C.N. Tomé, D.W. Brown, T.M. Holden, S.C. Vogel, Study of slip mechanisms in a magnesium alloy by neutron diffraction and modeling, Scr. Mater. 48 (2003) 1003-1008.

[41] Y. Chino, K. Kimura, M. Mabuchi, Twinning behavior and deformation mechanisms of extruded AZ31 Mg alloy, Mater. Sci. Eng. A. 486 (2008) 481-488.

[42] M.A. Gharghouri, G.C. Weatherly, J.D. Embury, J. Root, Study of the mechanical properties of Mg-7.7 at.\% Al by in-situ neutron diffraction, Philos. Mag. A. 79 (1999) 1671-1695. 
[43] R.E. Reed-Hill, E.P. Dahlberg, W.A. Slippy Jr, Some anelastic effects in Zirconium at room temperature resulting from prestrain at $77 \mathrm{deg}$ K, Trans. Met. Soc. AIME. 233 (1965) 1766-1770.

[44] Q. Ma, B. Li, A.L. Oppedal, W.R. Whittington, S.J. Horstemeyer, E.B. Marin, et al., Strain rate dependence of twinning at $450^{\circ} \mathrm{C}$ and its effect on microstructure of an extruded magnesium alloy, Mater. Sci. Eng. A. 559 (2013) 314-318.

[45] M.A. Meyers, O. Vöhringer, V.A. Lubarda, The onset of twinning in metals: a constitutive description, Acta Mater. 49 (2001) 4025-4039.

[46] I. Ulacia, N.V. Dudamell, F. Gálvez, F, S. Yi, M.T. Pérez-Prado, I. Hurtado, Mechanical behavior and microstructural evolution of a Mg AZ31 sheet at dynamic strain rates, Acta Mater. 58 (2010) 2988-2998.

[47] M.R. Barnett, A Taylor model based description of the proof stress of magnesium AZ31 during hot working, Metall. Mater. Trans. A. 34 (2003) 1799-1806.

[48] C. Bettles, M. Barnett (Eds.), Advances in wrought magnesium alloys: Fundamentals of processing, properties and applications, Woodhead Publishing, Cambridge, 2012.

[49] U.F. Kocks, A.S. Argon, M.F. Ashby, Thermodynamics and kinetics of slip, in: B. Chalmers, J.W. Christian, T.B. Massalski (Eds.), Progress in Materials Science, Pergamon Press, Oxford, 1975, pp. 110-170.

[50] J.W. Morris Jr, Overview of dislocation plasticity, in: K.H.J. Buschow, R. Cahn, M. Flemings, B. Ilschner, E. Kramer, S. Mahajan, P. Veyssiere (Eds.), Encyclopedia of Materials: Science and Technology, Pergamon Press, Oxford, 2001, pp. 4986-4994.

[51] Q. Zhou, J.J. Li, F. Wang, P. Huang, K.W. Xu, T.J. Lu, Strain rate sensitivity of Cu/Ta multilayered films: Comparison between grain boundary and heterophase interface, Scr. Mater. 111 (2016) 23-126.

[52] C.H. Cáceres, D.M. Rovera, Solid solution strengthening in concentrated $\mathrm{Mg}-\mathrm{Al}$ alloys, J. Light Metals. 1 (2001) 151-156.

[53] D. Nagarajan, C.H. Cáceres, J.R. Griffiths, Grain size hardening effects in $\mathrm{Mg}$ and its alloys [dissertation], University of Queensland, Brisbane, 2014.

[54] B. Li, H.E.I. Kadiri, X.Y. Zhang, S.N. Mathaudhu, Q. Ma, Structural origin of reversible twinning, non-schmid effect, incoherent twin boundaries and texture of hexagonal close-packed metals, in: S.N. Mathaudhu, W.H. Sillekens, N.R. Neelameggham, N. Hort N (Eds.), Magnesium Technology 2012: Proceedings of the TMS (The Minerals, Metals \& Materials Society), 2012 Mar 11-15, Orlando, Florida, p. 105-110.

[55] A. Kelly, G.W. Groves, P. Kidd, Crystallography and crystal defects, John Wiley \& Sons, New Jerseys, 2000.

[56] S.M. Zhu, M.A. Easton, T.B. Abbott, M.A. Gibson, J.F. Nie, The influence of individual rare earth elements ( $\mathrm{La}, \mathrm{Ce}$, or $\mathrm{Nd}$ ) on creep resistance of die-cast magnesium alloy AE44, Adv. Eng. Mater. 18 (2016) 932-937.

[57] S.M. Zhu, M.A. Easton, T.B. Abbott, J.F. Nie, M.S. Dargusch, N. Hort, et al., Evaluation of magnesium die-casting alloys for elevated temperature applications: microstructure, tensile properties, and creep resistance, Metall. Mater. Trans. A. 46A (2015) 3543-3554.

[58] B. Zhang, S. Gavras, A.V. Nagasekhar, C.H. Cáceres, M.A. Easton, The strength of the spatially interconnected eutectic network in HPDC Mg-La, Mg-Nd, and Mg-La-Nd alloys, Metall. Mater. Trans. A. 45 (2014) 4386-4397.

[59] B. Zhang, A.V. Nagasekhar, X.M. Tao, Y.F. Ouyang, C.H. Cáceres, M.A. Easton, Strengthening by the percolating intergranular eutectic in an hpdc $\mathrm{Mg}-\mathrm{Ce}$ alloy, Mater. Sci. Eng. A. 599 (2014) 204-211.

[60] M.A. Meyers, Dynamic Behaviour of Materials, John Wiley \& Sons, New York, 1994. 
[61] J.D. Robson, N. Stanford, M.R. Barnett, Effect of precipitate shape on slip and twinning in magnesium alloys, Acta Mater. 59 (2011) 1945-1956.

[62] J.F. Nie, Effects of precipitate shape and orientation on dispersion strengthening in magnesium alloys, Scr. Mater. 48 (2003) 1009-1015.

[63] N. Stanford, M.R. Barnett, Effect of particles on the formation of deformation twins in a magnesium-based alloy, Mater. Sci. Eng. A. 516 (2009) 226-234.

[64] J.D. Robson, N. Stanford, M.R. Barnett, Effect of particles in promoting twin nucleation in a Mg-5wt.\% Zn alloy, Scr. Mater. 63 (2010) 823-826. 
Table 1. Chemical compositions (wt.\%) determined by ICP-AES for the studied die-cast $\mathrm{Mg}$ alloys.

\begin{tabular}{cccccc}
\hline Alloy & Al & Mn & RE $($ Ce+La $)$ & Zn & Mg \\
\hline AM40 & 4.44 & 0.21 & $<0.01$ & 0.05 & Bal. \\
AM60 & 6.26 & 0.29 & $<0.01$ & 0.1 & Bal. \\
AZ91 & 8.88 & 0.19 & $<0.01$ & 0.74 & Bal. \\
AE44 & 3.67 & 0.31 & 3.83 & $<0.01$ & Bal. \\
\hline
\end{tabular}


Table 2. Stresses and strains at the onsets of stage II and stage III from repeated tests calculated using formalism proposed in literature [3, 13, 37].

\begin{tabular}{cccccc}
\hline \multirow{2}{*}{ Alloy } & $\begin{array}{c}\text { Strain } \\
\text { rate }\left(\mathbf{s}^{-1}\right)\end{array}$ & \multicolumn{2}{c}{ Stage II Onset } & \multicolumn{2}{c}{ Stage III Onset $^{*}$} \\
\cline { 3 - 6 } & $10^{-6}$ & $47 \pm 2.50$ & $0.12 \pm 0.01$ & $126 \pm 0.00$ & $0.90 \pm 0.02$ \\
\multirow{2}{*}{ AM40 } & $10^{-2}$ & $40 \pm 0.00$ & $0.11 \pm 0.02$ & $132 \pm 1.00$ & $0.93 \pm 0.02$ \\
& & & & & \\
\multirow{2}{*}{ AM60 } & $10^{-6}$ & $43 \pm 0.50$ & $0.10 \pm 0.01$ & $147 \pm 1.00$ & $1.02 \pm 0.08$ \\
& $10^{-1}$ & $46 \pm 4.50$ & $0.11 \pm 0.10$ & $155 \pm 1.50$ & $1.01 \pm 0.03$ \\
& & & & & \\
AZ91 & $10^{-6}$ & $66 \pm 4.00$ & $0.17 \pm 0.02$ & $195 \pm 3.00$ & $1.25 \pm 0.07$ \\
& $10^{-1}$ & $65 \pm 5.00$ & $0.16 \pm 0.02$ & $198 \pm 0.00$ & $1.29 \pm 0.02$ \\
AE44 & $10^{-6}$ & $44 \pm 1.00$ & $0.10 \pm 0.01$ & $145 \pm 3.50$ & $0.79 \pm 0.04$ \\
& $10^{-1}$ & $36 \pm 4.00$ & $0.09 \pm 0.02$ & $172 \pm 0.00$ & $1.14 \pm 0.08$ \\
& & & & & \\
AE44-T5 & $10^{-6}$ & $72 \pm 1.00$ & $0.14 \pm 0.01$ & $174 \pm 2.00$ & $0.82 \pm 0.04$ \\
& $10^{-1}$ & $72 \pm 1.00$ & $0.16 \pm 0.00$ & $209 \pm 2.50$ & $1.28 \pm 0.13$
\end{tabular}

"The onset values of stage II are taken as the departure from pure elasticity while the onset values of stage III are taken as the start of linear hardening region on the tensile flow curve. 
Table 3. The type of twins formed in high strain rate-sensitive AE44 after cyclic deformation to $3 \%$ strain and the twinned area fraction determined by EBSD mapping.

\begin{tabular}{ccccc}
\hline \multirow{2}{*}{$\begin{array}{c}\text { Strain rate } \\
\left(\mathbf{s}^{-\mathbf{1}}\right)\end{array}$} & \multicolumn{3}{c}{ Twinned area fraction $(\%) \pm$ standard } & $\begin{array}{c}\text { Total twinned } \\
\text { deviations }\end{array}$ \\
\cline { 2 - 4 } & $\{10 \overline{1} 2\}$ & $\{10 \overline{1} 1\}$ & $\{10 \overline{1} 3\}$ & $2.6 \pm 0.11$ \\
\hline $\mathbf{1 0}^{-\mathbf{6}}$ & $1.9 \pm 0.10$ & $0.5 \pm 0.03$ & $0.2 \pm 0.02$ & $3.4 \pm 0.07$ \\
$\mathbf{1 0}^{-\mathbf{1}}$ & $3.1 \pm 0.10$ & $0.2 \pm 0.05$ & $0.1 \pm 0.02$ & \\
\hline
\end{tabular}




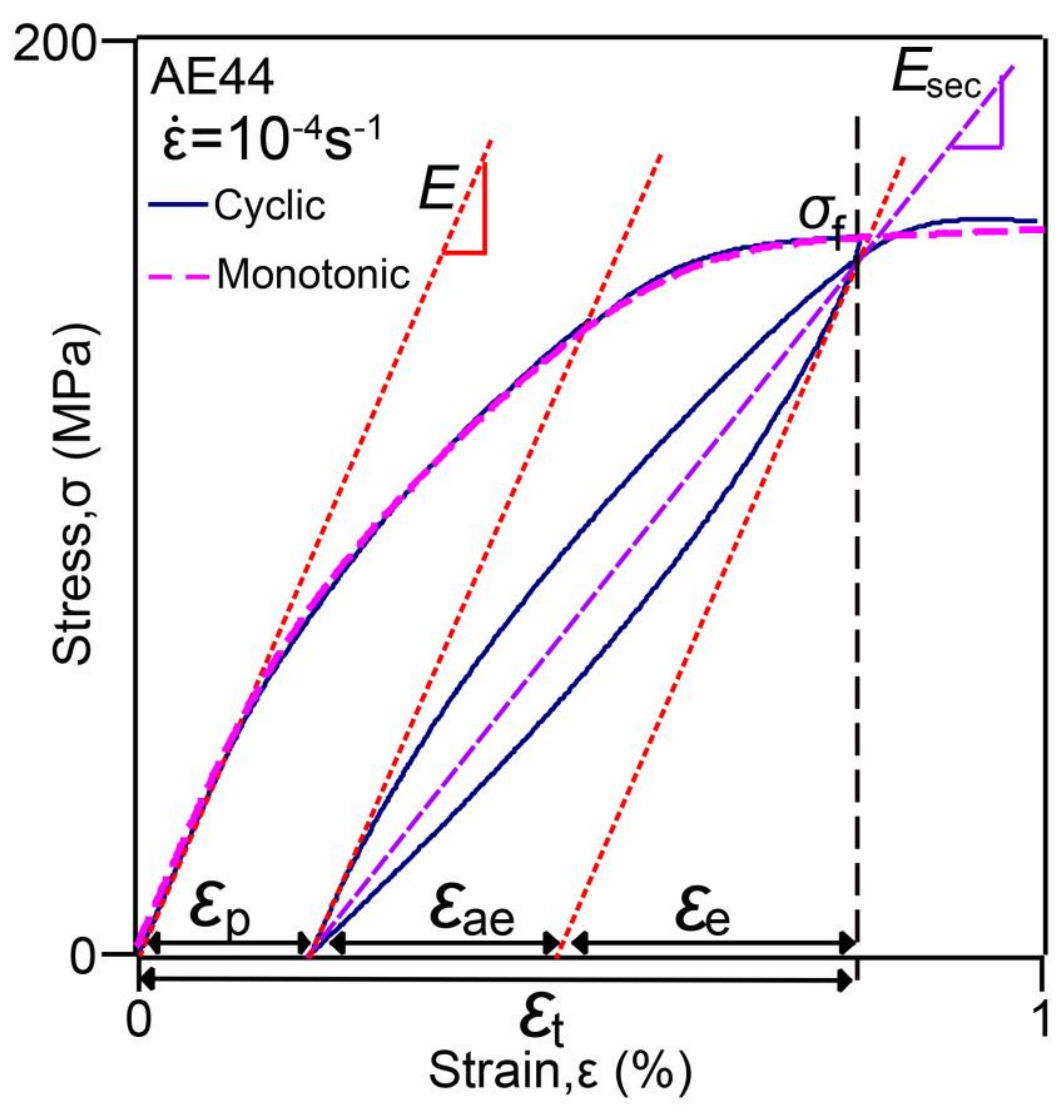

Fig. 1. An overview of cyclic stress-strain curve of die-cast AE44 at $10^{-4} \mathrm{~s}^{-1}$, where the total strain $\left(\varepsilon_{\mathrm{t}}\right)$ can be separated into linear elastic strain $\left(\varepsilon_{\mathrm{e}}\right)$, anelastic strain $\left(\varepsilon_{\mathrm{ae}}\right)$ and plastic strain $\left(\varepsilon_{\mathrm{p}}\right) . E$ is the nominal elastic modulus of $\mathrm{Mg}$, taken as $45 \mathrm{MPa}[38,39]$, while $E_{\text {sec }}$ is the secant elastic modulus. $\sigma_{\mathrm{f}}$ is defined as the applied stress where unloading starts. The dashed line is the monotonic tensile flow curve. 

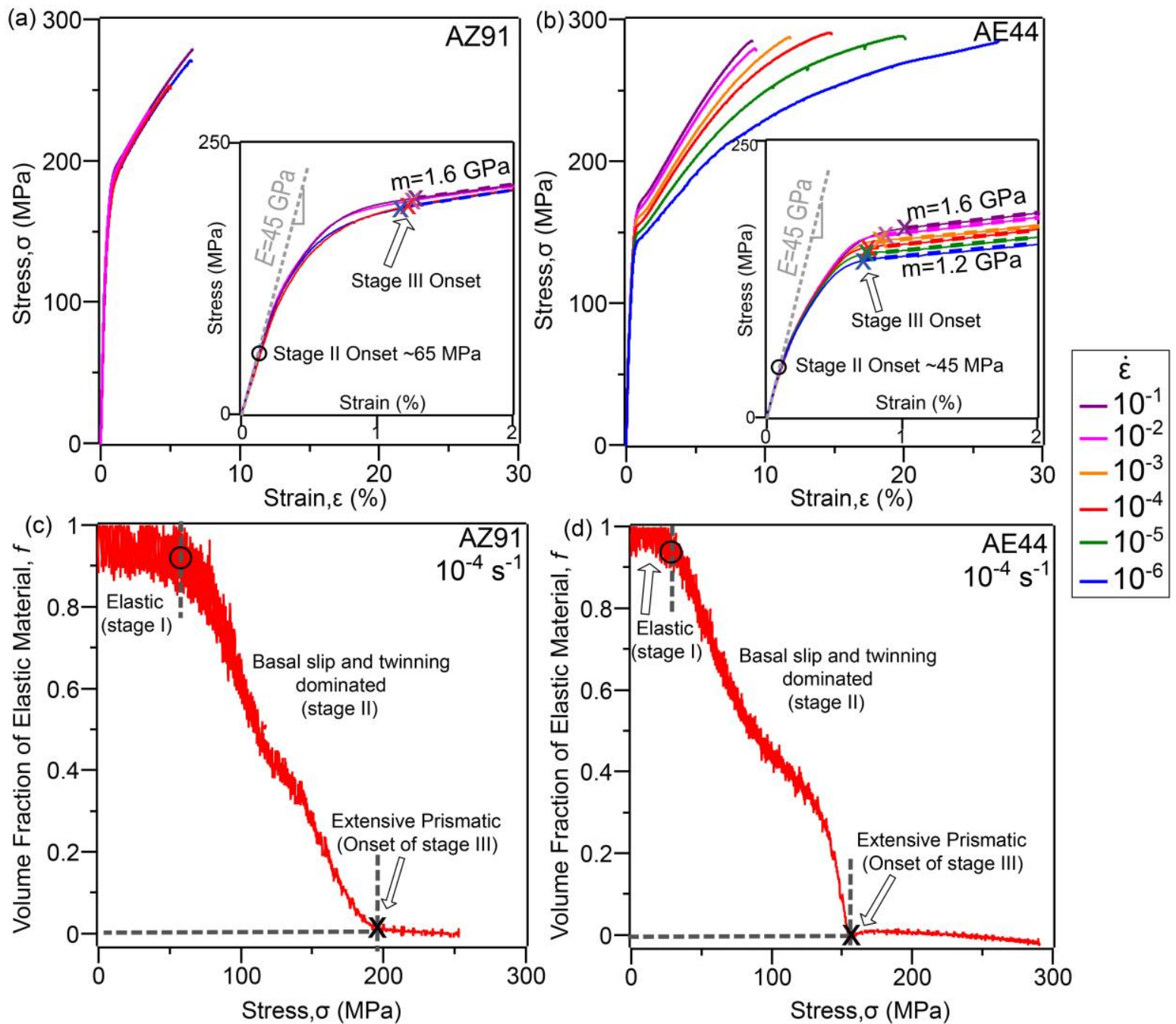

Fig. 2. Monotonic flow curves of (a) AZ91 and (b) AE44 at strain rates $10^{-6}-10^{-1} \mathrm{~s}^{-1}$ which can be separated into different region as illustrated by the volume fraction of (c) AZ91 and (d) AE44 that remained elastic as a function of stress (calculated with Eq. (1)). Onsets of stages II and III are marked by 'O' and ' $\mathrm{X}$ ', respectively. 

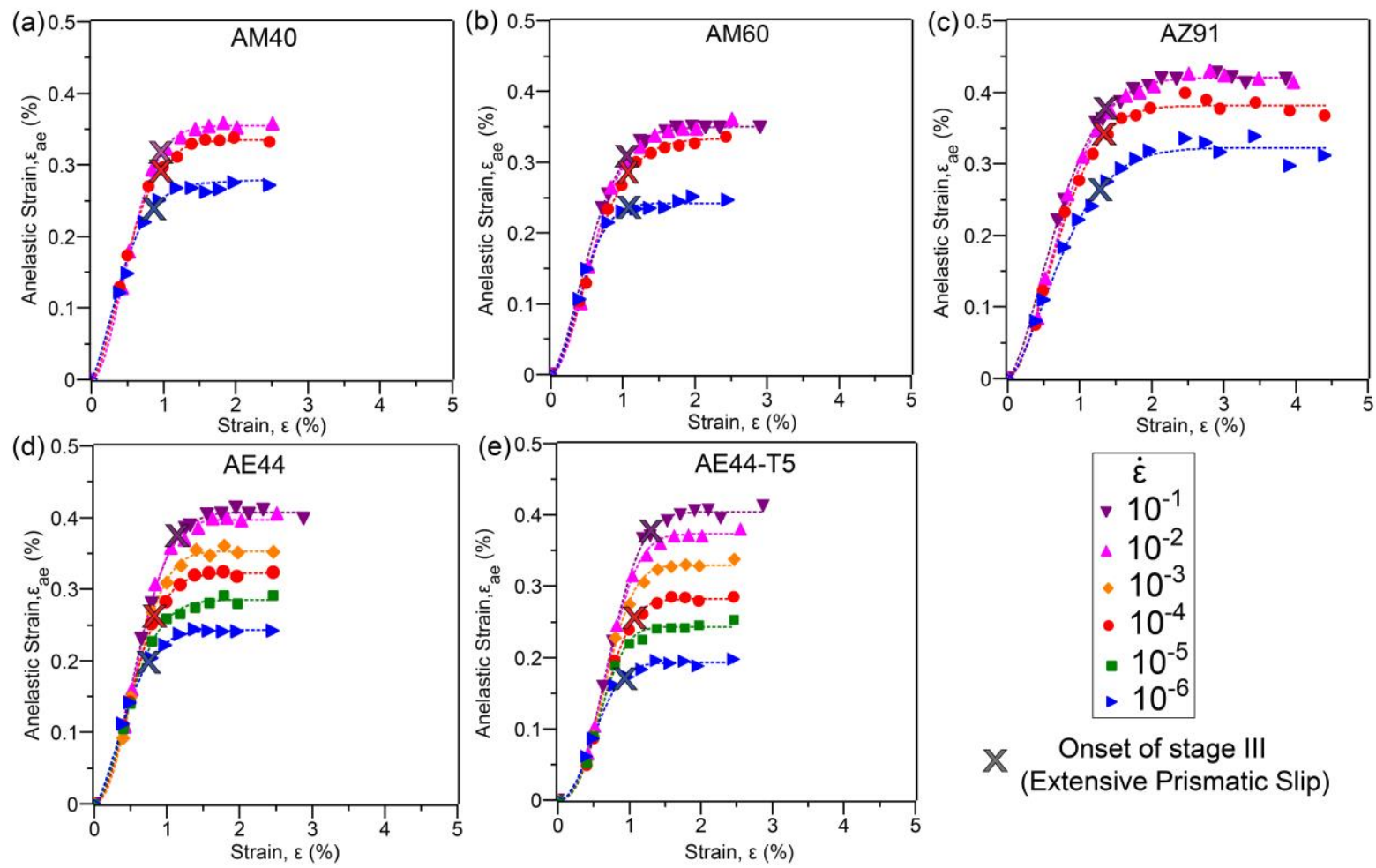

X Onset of stage III

(Extensive Prismatic Slip)

Fig. 3. Anelastic strain (defined in Fig. 1) as a function of strain, for as-cast (a) AM40, (b) AM60, (c) AZ91, (d) AE44 and (e) T5-aged AE44, at strain rate range $10^{-6}-10^{-1} \mathrm{~s}^{-1}$. Onset of stage III, extensive prismatic slip (defined in Fig. 2) is marked by symbol ' $\mathrm{X}$ '. 


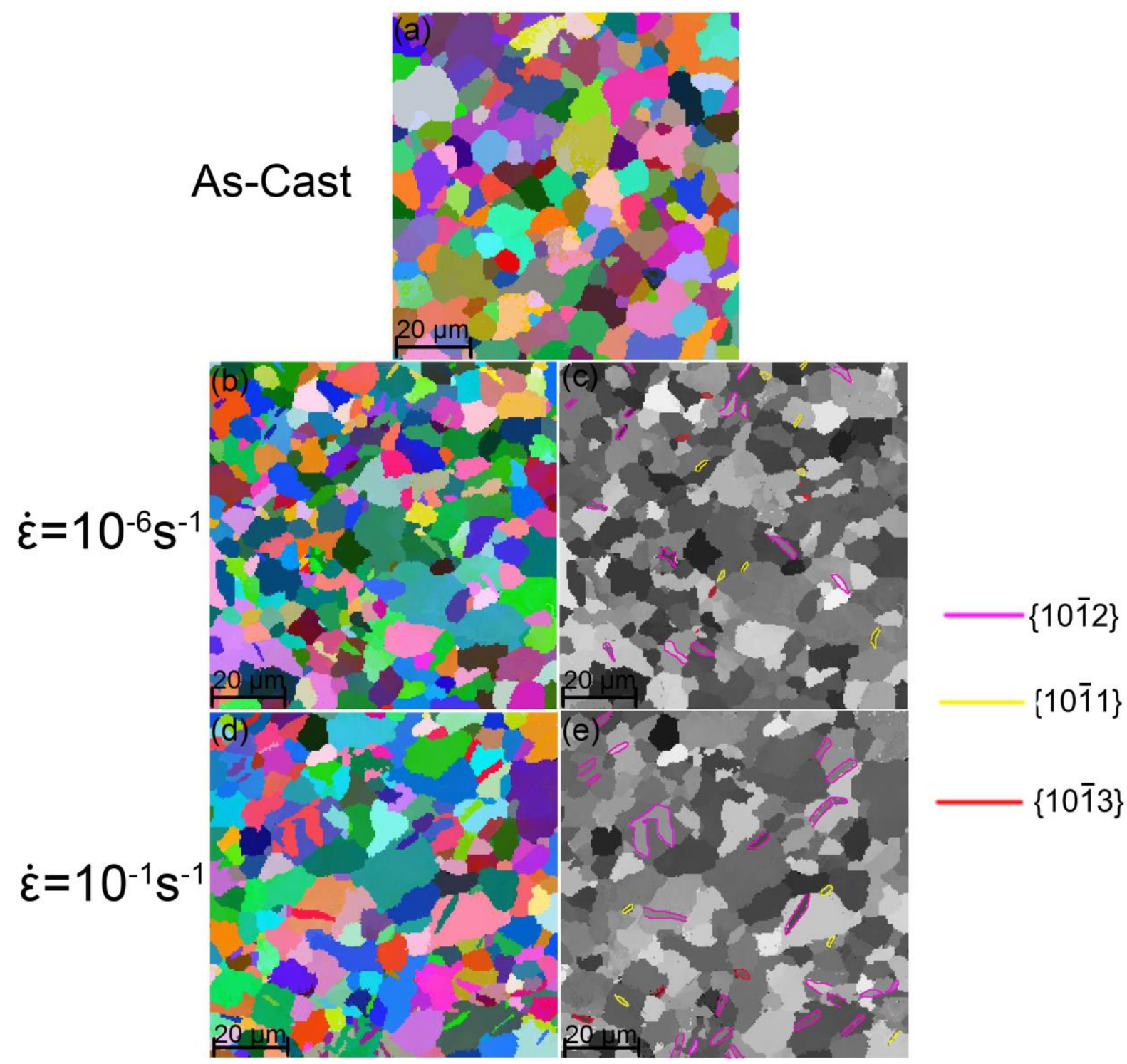

Fig. 4. EBSD maps of AE44 showing (a) twin-free microstructure in as-cast condition and the formation of different types of twins at $(\mathrm{b}, \mathrm{c}) 10^{-6} \mathrm{~s}^{-1}$ and $(\mathrm{d}, \mathrm{e}) 10^{-1} \mathrm{~s}^{-1}$ after cyclic testing to $3 \%$ strain. The loading direction is horizontal. 

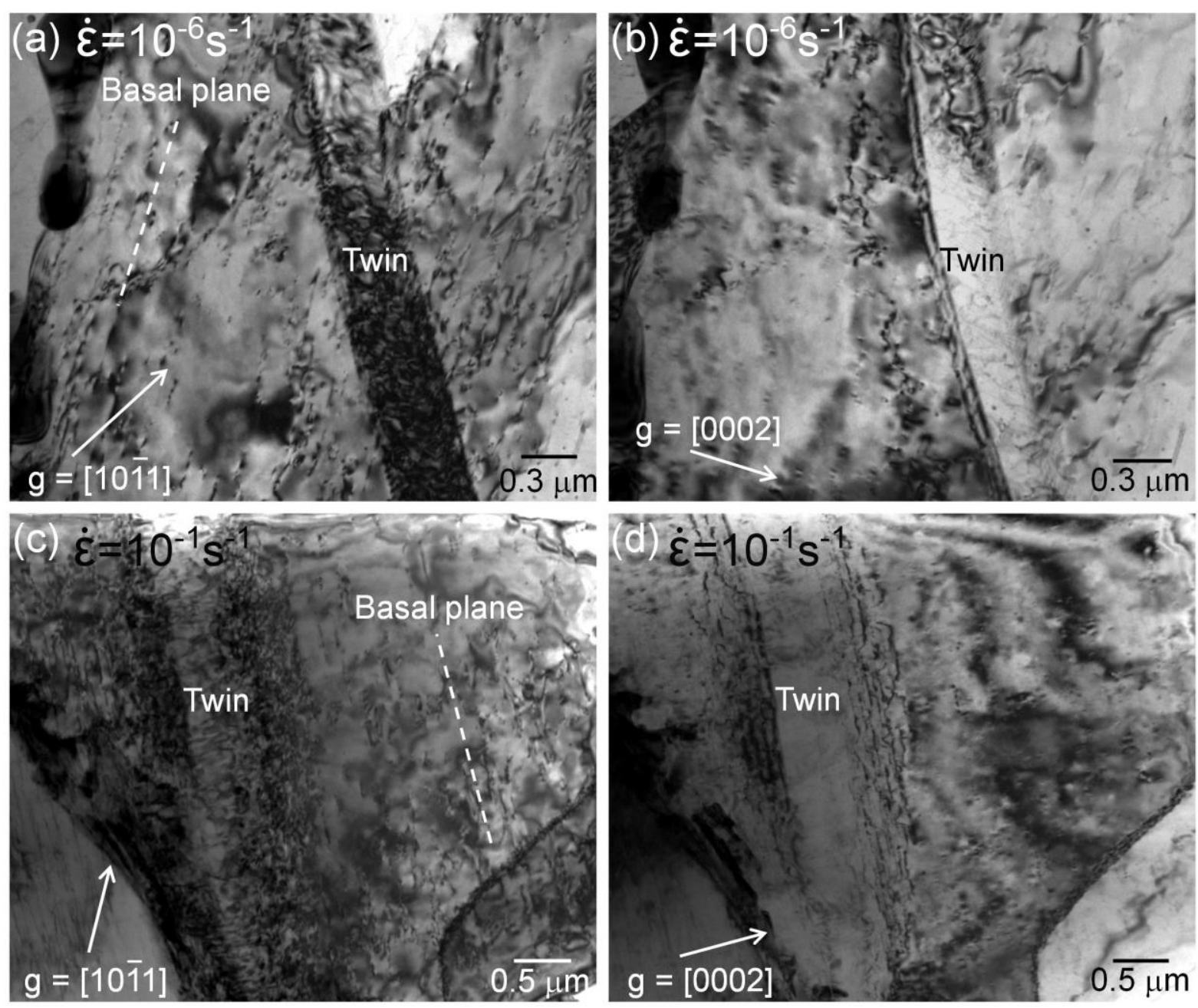

Fig. 5. TEM observations of dislocations pile-ups at twin and grain boundaries in AE44 cyclic tested to $3 \%$ strain at (a) $10^{-6} \mathrm{~s}^{-1}$ and (c) $10^{-1} \mathrm{~s}^{-1}$ when viewed with $\mathbf{g}=$ [1011]. (b) and (d) are the same area but viewed with $\mathbf{g}=[0002]$. 

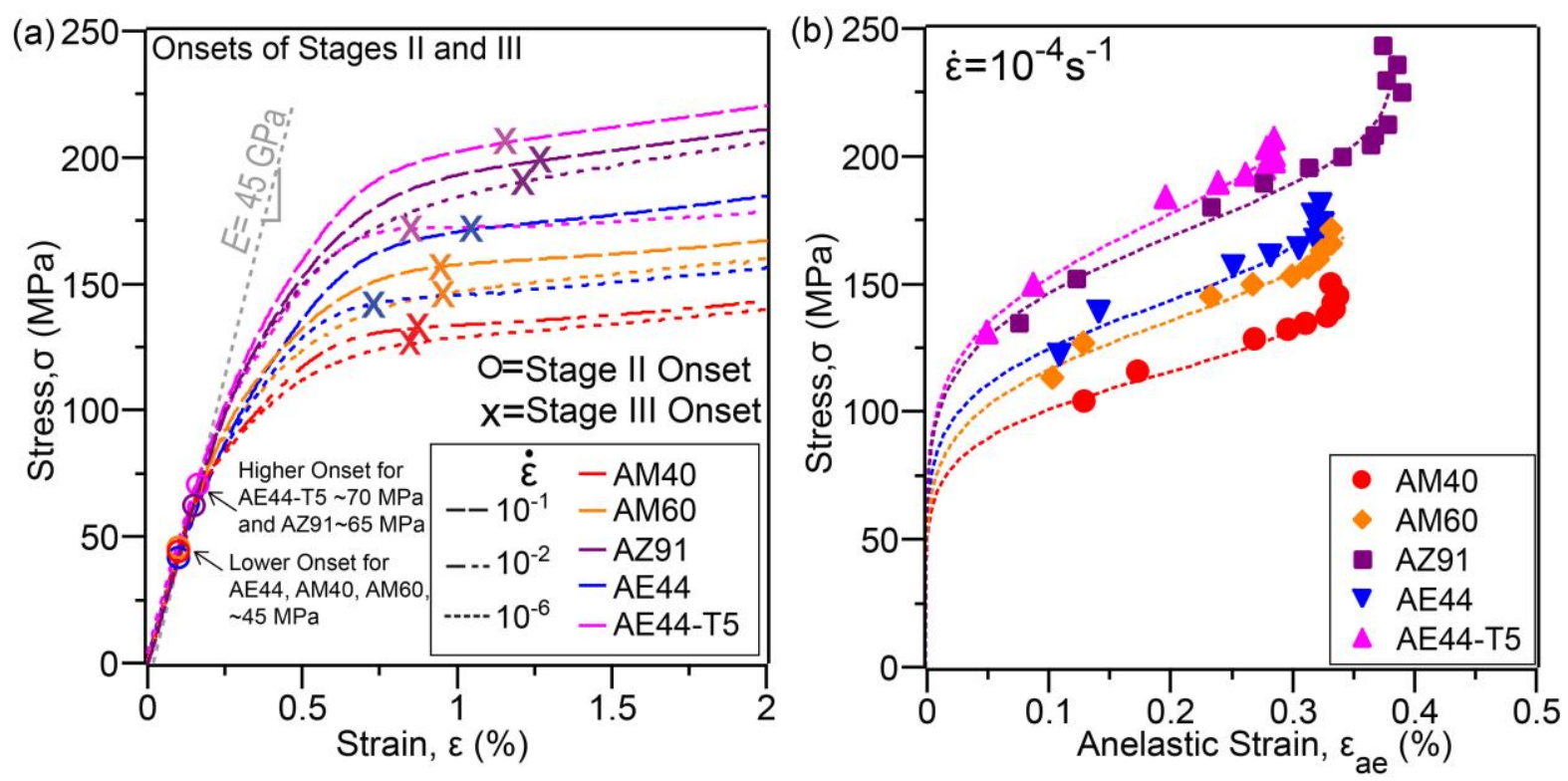

Fig. 6. A correlation between onsets of stages II and III with anelastic strain. (a) Monotonic tensile flow curve with the onsets of stage II marked by ' $\mathrm{O}$ ' and stage III marked by ' $\mathrm{X}$ ' and (b) stress as a function of anelastic strain at strain rate $10^{-4} \mathrm{~s}^{-1}$. For onset values, refer to Table 2. 


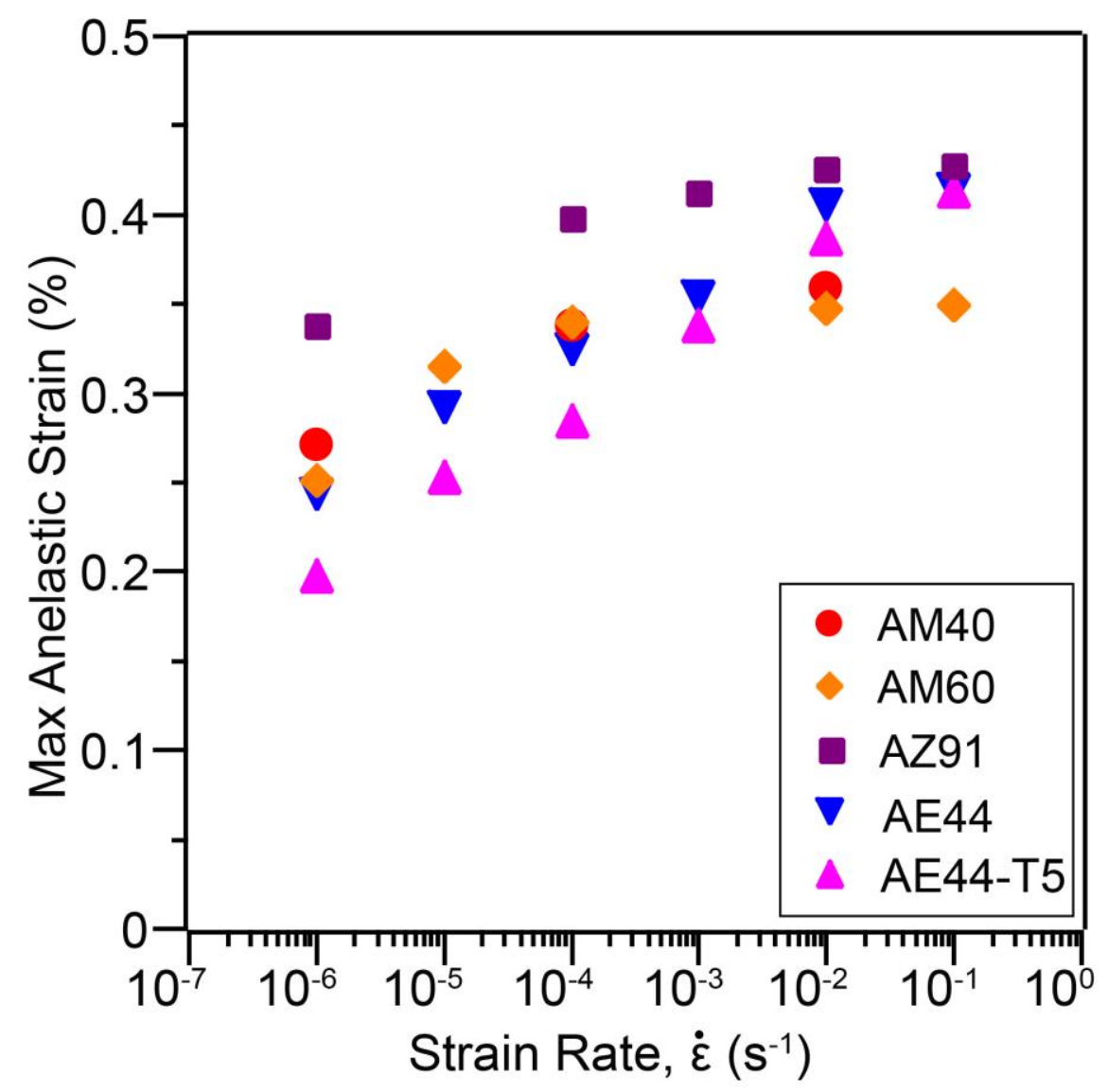

Fig. 7. Maximum anelastic strain as a function of strain rate, for all alloys tested. 

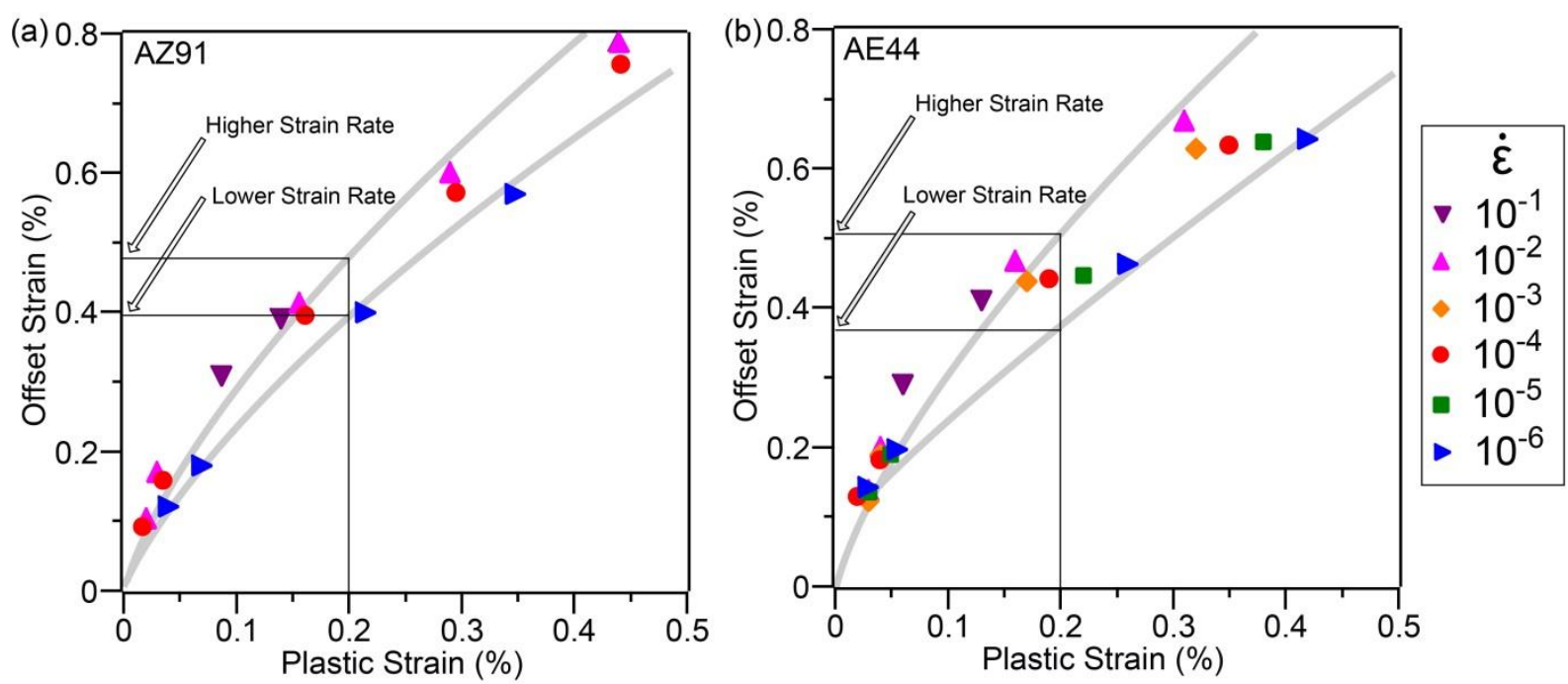

Fig. 8. Offset strain (plastic strain + anelastic strain) as a function of permanent plastic strain for (a) AZ91 and (b) AE44 at strain rate range $10^{-6}-10^{-1} \mathrm{~s}^{-1}$. 